\title{
Holocene dust dynamics archives in archaeological ruins in arid and semi-arid environments in the Southern Levant
}

\author{
Bernhard Lucke $^{1}$ (]) $\cdot$ Rupert Bäumler ${ }^{1}$
}

Received: 7 April 2021 / Accepted: 8 November 2021 / Published online: 29 November 2021

(c) The Author(s) 2021

\begin{abstract}
Ruins of archaeological structures, mainly dating to the Bronze Age till Byzantine period, were investigated in a case study in the Petra region in southern Jordan and in the northern Negev desert in Israel. They are covered by post-abandonment debris sediments which provided the parent material of initial soils now developed on the ruins. Such debris sediments have so far rarely been studied although they likely contain a significant aeolian dust fraction because structures and wall remains may act as effective dust traps. We analyzed different types of archaeological structures: cult sites on hilltops, runoff-irrigated terraces on slopes, and cisterns including associated cleanout mounds. As well, we collected current aeolian sediments in nearby dry marble dust traps. It was expected that the various ruins and location types would matter for sediment properties, but substrate composition in all investigated structures was similar. This suggests that most of the fine fractions of the debris material were primarily supplied by wind whereas fluvial processes only re-distributed aeolian sediments. A major aeolian contribution from local weathered rocks could be observed in the Petra region, but not in the Negev, which seems connected with the geology. In situ pedogenesis in both investigation regions is negligible. The ruins seem to act as current dust collectors, but their sediments cannot directly be compared with the material collected in nearby dry marble dust traps. Analogies to different types of collectors for aeolian sediments can be made: depending on design, dust traps gather aeolian material differently. Standard dry marble dust collectors are characterized by similar size of settling dust samples as compared to average aeolian deposition in the ruins, but are of dissimilar substrate composition with regard to particle size distribution and contents of major and trace elements. Sediments in the archaeological structures in southern Jordan show finer textures and higher contents of most major and trace elements which may indicate preferential fixation of silt and clay against sand in the ruins, whereas sediments in dry marble dust collectors in Jordan are relatively depleted in silt and clay. This could be due to crusts and clast covers because the studied archaeological hilltop structures were found covered by surface crusts and pavements of stones and pottery sherds. These may mirror the effect of desert pavements. In addition, current dust samples suggest that precipitation during aeolian sedimentation, in particular in case of snow, is connected with enhanced deposition of (possibly clay-coated) silt. Sediments in the archaeological structures include material from remote and local sources as well as from "recycled" paleosols. Average hilltop dust accretion rates were calculated as $\sim 0.14 \mathrm{~mm} / \mathrm{year}$, which is in good agreement with results from dry marble dust collectors. They exceed rates calculated for Pleistocene hilltop loess in the Negev. This seems due to enhanced dust fixation in the archaeological ruins as compared to natural Negev loess soils, underlining a so far rarely considered but important role of sediment fixation mechanisms.
\end{abstract}

Keywords Dust deposition $\cdot$ Aeolian sedimentation $\cdot$ Dust collector $\cdot$ Holocene $\cdot$ Archaeological ruins $\cdot$ Environmental archive

Communicated by Stefan Grab.

This paper was selected from the 3rd Conference of the Arabian Journal of Geosciences (CAJG), Tunisia 2020

Bernhard Lucke

bernhard.lucke@fau.de

1 Institute of Geography, FAU Erlangen-Nürnberg, Wetterkreuz 15, 91058 Erlangen, Germany

\section{Introduction}

Many arid zones are characterized by thin, weakly developed soils (Goudie 2013). However, some host well-developed soils on loess-like deposits, such as the Negev desert in the southern Levant. These soils derived from aeolian sediments were analyzed in various studies (Yaalon and Dan 
1974; Bruins 1976; Bruins and Yaalon 1979, 1992; Goldberg 1986; Goodfriend and Magaritz 1988; Issar and Bruins 1983; Bowman et al. 1986; Gerson and Amit 1987; Zilberman 1992; Crouvi et al. 2008, 2009). In Jordan, loess-like sediments were postulated (Bender 1974; Cordova 2007), but have sparsely been documented (see summaries in Lucke et al. 2013; and Lucke et al. 2019a, b).

The processes leading to loess formation in the Levant are still discussed. The genesis of loss-like soils in this region is often considered to be connected with enhanced dust supply (Smalley et al. 2019; Lancaster 2020), and the debate therefore focuses on potential dust sources. Pleistocene abrasion of silt-sized quartz from moving sand in the SinaiNegev dune field has been brought forward as major dustgenerating process (Crouvi et al. 2008; Enzel et al. 2010; Amit et al. 2021), but ages of dune mobilization (Roskin 2021), quartz generation during wind tunnel experiments (Swet et al. 2019; Adams and Soreghan 2020), and regional soil distribution (Lucke 2021) are not in agreement with this hypothesis. Silt deposition may have been mainly a result of medium-range transport (Roskin et al. 2014). It should be noted that Holocene deposits of settled dust are largely absent in the Negev (Faershtein et al. 2016; Erickson-Gini and Porat 2018). This absence of Holocene loess deposits in the Negev could be connected with more concentrated rainfalls favoring erosion against sediment accumulation (Avni et al. 2006). Present-day synoptic dust mobilization is often used as a model to explain Pleistocene dust processes in the Levant, despite the uncertainties and differences regarding wind patterns between those in the Holocene and those in the Pleistocene. Therefore, identification and evaluation of Holocene dust records in the Levant could significantly improve our understanding of aeolian deposition and its role for pedogenesis in this region, in particular regarding the interpretation of Pleistocene loessial paleosols in the Negev.

When irrigation from cisterns or by collected runoff is possible, the Negev loess provides fertile soils for agriculture. During antiquity, well-maintained agricultural terraces reduced runoff and thus incision and erosion (Avni et al. 2019). In this context, sediments accumulating behind terrace walls may contain a significant portion of aeolian dust, even if it is partly reworked (Bruins and Jongmans 2012). As well, aeolian dust may accumulate in ruins of houses and other built structures (Lucke et al. 2005; Lucke 2008; Porat et al. 2013; Junge et al. 2016, 2018; Erickson-Gini and Porat 2018; Lucke et al. 2019a, b).

Loess-like sediments in archaeological structures could represent the missing Holocene dust records. A comparison of sediments in archaeological structures with Pleistocene loess and current dust could therefore significantly improve our understanding of dust deposition in the Levant. We followed this approach by conducting a systematical comparison of sediments in different archaeological structures in southern Jordan and the Negev with natural soils and current aeolian sedimentation gathered in dry marble dust collectors. While detailed results with regard to particle sizes and chemical composition have been published elsewhere (Lucke et al. 2019a, b), this contribution provides a synthesis focusing on the basic research approach regarding the suitability of several types of archaeological structures as reliable dust traps allowing to better understand Holocene aeolian sedimentation processes.

\section{Study sites, geology, and methods}

Earlier studies indicated that aeolian dust may have accumulated in archaeological structures in the northern Negev (Bruins and Jongmans 2012) while potential loess-like sediments were mapped, but not investigated, in southern Jordan (Bender 1974; Cordova 2007). Therefore, we investigated sediments potentially comprising Holocene dust from the following archaeological structures in the two study regions in the northern Negev and the Petra area in southern Jordan (Fig. 1):

- Ruins on hilltops: aeolian sediments were deposited after their abandonment.

- Agricultural terraces: sediments accreted until they reached the top of the terrace walls.

- Cisterns: sediments were on the one hand cleaned out and accumulated in nearby mounds during cistern use, and cisterns were filled by sediments after they fell in disuse.

Close to the archaeological sites, three dry marble dust collectors were set up and continuously sampled. In addition, natural soils and geological outcrops surrounding the site in up to 200-m distance were sampled as references. Only abbreviated site descriptions are provided here, and the sampled sites listed in Table 1 (Petra region in southern Jordan) and Table 2 (northern Negev), while their locations are shown in Fig. 1. Detailed descriptions of the sampled profiles can be found in Lucke et al. (2019a, b). Photos of the archaeological structures and their sediment fills are provided in Figs. 2, 3, and 4 for study sites in southern Jordan, and in Fig. 5 for study sites in the northern Negev.

We tried to evaluate sediment fills of disused subterranean rock-cut cisterns near Petra, but that proved a difficult task as most cisterns had been cleaned and re-used rather recently by local Bedouin. Finally, it was possible to locate a subterranean cistern filled with sediment that had 


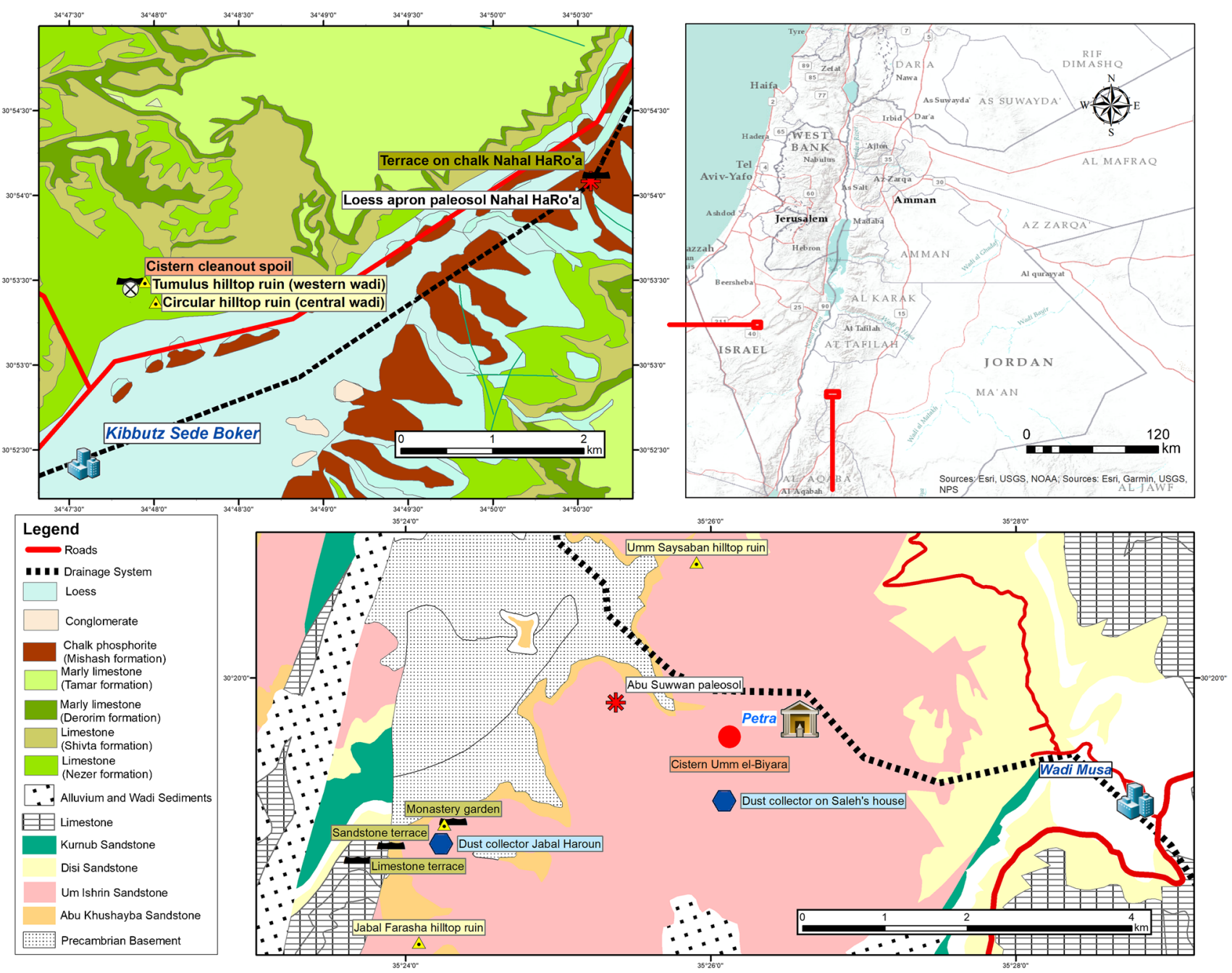

Fig. 1 Map of the study areas, showing major geological units (after Barjous 2003, and Avni and Weiler 2013) and the sampling sites: dotted triangles mark hilltop ruins, walls show terraces, circles indicate cisterns, asterisks mark reference sites, and hexagons current dust traps. The dust sampler in the Negev is located $\sim \mathrm{km}$ south in Midreshet Ben Gurion. Sources and copyright of the topographical and terrain basemaps: Esri, USGS, NOAA, Garmin, NPS; used according to Esri Master License Agreement
Table 1 List of studied archaeological structures in the Petra region in southern Jordan, including type of ruin and probable construction period (according to building styles and associated material culture).
The ages of the paleosols were estimated from the archaeological sites that buried them

\begin{tabular}{lllll}
\hline Petra region, southern Jordan & & & \multicolumn{2}{c}{ Coordinates } \\
\cline { 1 - 1 } Name & Ruin type & Construction period & & ${ }^{\circ} \mathrm{N}$ \\
\hline Jabal Farasha hilltop ruin & Hilltop ruin & Nabatean & 30.30445 \\
Umm Saysaban hilltop ruin & Hilltop ruin & Bronze Age & 35.40141 \\
Jabal Haroun monastery & Hilltop ruin & Byzantine & 30.34595 \\
Monastery garden & Cistern-irrigated terrace & Late Roman & 30.31734 \\
Limestone terrace & Runoff-irrigated terrace & Nabatean & Nabatean & 35.43178 \\
Sandstone terrace & Runoff-irrigated terrace & Nabatean & 30.31665 \\
Cistern on Umm el-Biyara & Subterranean cistern fill & $>10,000$ years & 35.40518 \\
Abu Suwwan paleosol & Natural reference soil & $>10,000$ years & 35.31244 \\
Shkarat Msaeid paleosol & Natural reference soil & Unknown, probably recent age & 30.31404 \\
Sandplateau: natural hilltop soil & Natural reference soil & 30.32690 & 35.39839 \\
\hline
\end{tabular}


Table 2 List of studied archaeological structures in the northern Negev in Israel, including type of ruin and probable construction period (according to building styles and associated material culture)

\begin{tabular}{|c|c|c|c|c|}
\hline \multicolumn{3}{|l|}{ Northern Negev, Israel } & \multicolumn{2}{|c|}{ Coordinates } \\
\hline Name & Ruin type & Construction period & ${ }^{\circ} \mathrm{N}$ & ${ }^{\circ} \mathrm{N}$ \\
\hline Tumulus hilltop ruin (western wadi) & Hilltop ruin & Bronze Age & 30.89151 & 34.79909 \\
\hline Circular hilltop ruin (central wadi) & Hilltop ruin & Bronze Age & 30.88948 & 34.80015 \\
\hline Terrace on chalk in Nahal Haro'a & Runoff-irrigated terrace & Byzantine & 30.90111 & 34.8435 \\
\hline Terrace 3 (western Wadi) & Runoff-irrigated terrace & Iron Age & 30.89069 & 34.79769 \\
\hline Cistern cleanout spoil & Cistern cleanout & Byzantine & 30.89114 & 34.79768 \\
\hline Loessial apron in Nahal Haro'a & Natural reference soil & Late Pleistocene & 30.90140 & 34.84296 \\
\hline
\end{tabular}

Fig. 2 Profiles sampled in the Petra region in Southern Jordan. (A) Natural hilltop sandstone soil. Note some Juniperus trees to the right and the large Pistacia atlantica tree in the background. (B) Soil in wall remains on the site of Umm Saysaban, and (C) soil in the triclinium of Jabal Farasha. Note the clastcovered surface. (D) A paleosol below the partly excavated site of Shkarat Msaeid. The tape measure is in $\mathrm{cm}$. Figure re-published from Lucke et al. 2019b (Figure A1), creative commons license CC-BY

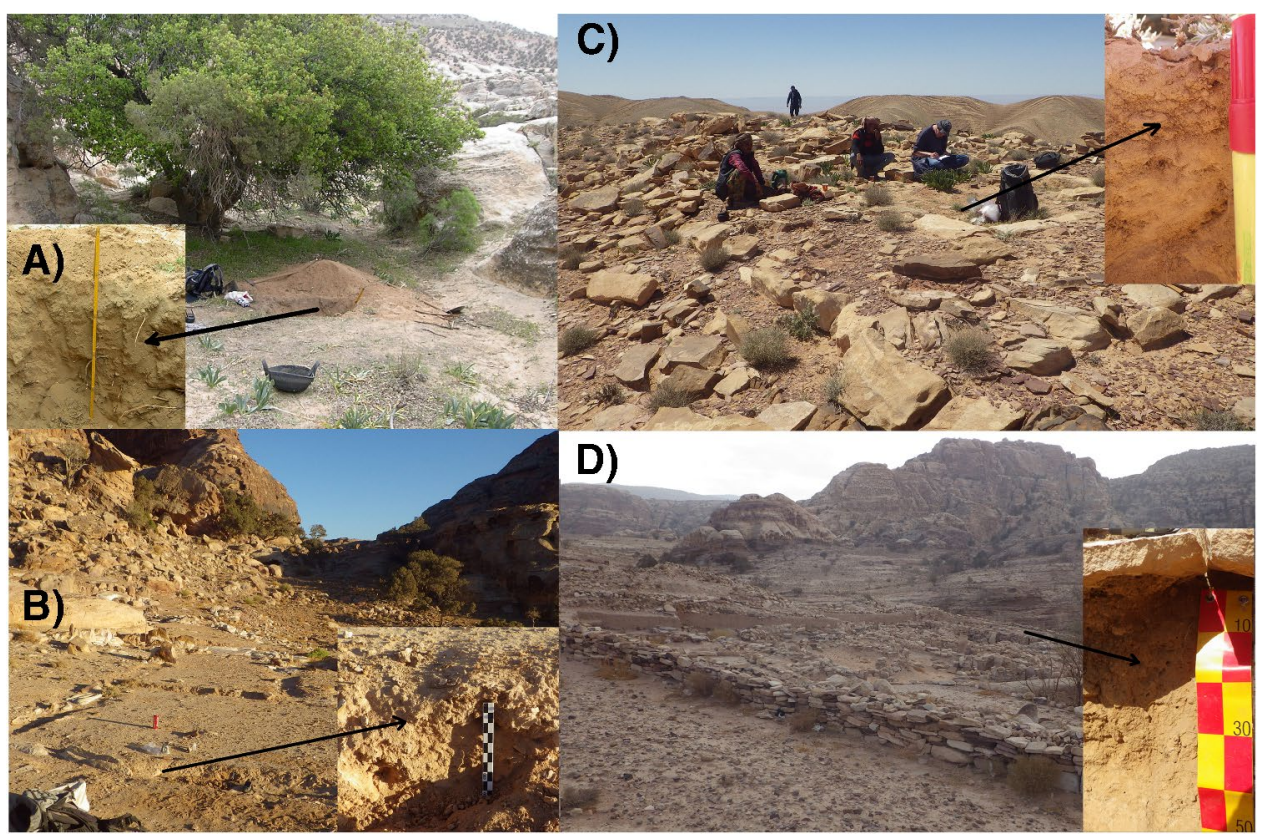

apparently not been cleaned for a long time on the mountain Umm al-Biyara, which overlooks the ancient city center of Petra (Fig. 4). However, the profile showed unclear stratigraphy. That was connected with the disposal of garbage and, apparently, with repeated cleaning and thrashing activities, leading to mixtures of old and recent sediments.

The geology of the northern Negev consists of massive to well-bedded shallow marine Turonian limestones (Avni and Weiler 2013) which include a continental clastic unit of sandstone and paleosols in elevations of 450-600 m (Sandler 1996). In some areas, patches of Late Pleistocene colluvial-aeolian aprons with loessial paleosols were preserved which indicate that the area was covered by loess blankets in the past (Bowman et al. 1986).

Cambrian continental sandstones of 900-1200-m elevation dominate the geology of southern Jordan near Petra. Patches of limestones and igneous rocks are present as well, partly connected with Horst structures related to the Dead Sea fault (Barjous 2003). The arid climate of both study regions is classified as BWh according to the Köppen-Geiger system.
The description of profiles applied Keys to Soil Taxonomy (Soil Survey Staff 2014) but used the concept of V-horizons for vesicular layers as recently proposed by Turk et al. (2016). Soil types were classified according to the World Reference Base of Soil Resources (WRB 2015). Color, bulk density, pH, organic matter, electrical conductivity, contents of calcium carbonate, and chemical composition of the studied sediments were determined according to standard methods. Grain sizes were analyzed by wet sieving (sand fractions), using both a Malvern MasterSizer 3000 laser diffraction analyzer and a Sedigraph grain size analyzer, without removal of $\mathrm{CaCO}_{3}$ (silt and clay fractions). Various methods of statistical analysis were applied: Gradistat for Excel and EMMAgeo v0.94 R package for grain size distributions including end-member analysis and principle component analysis (PCA) using the R-function prcomp to identify sample similarities. Types of deposits were statistically modeled using the $\mathrm{R}$ package randomForest. A detailed description of pedological, sedimentological, and statistical methods is provided in Lucke et al. (2019a, b). 


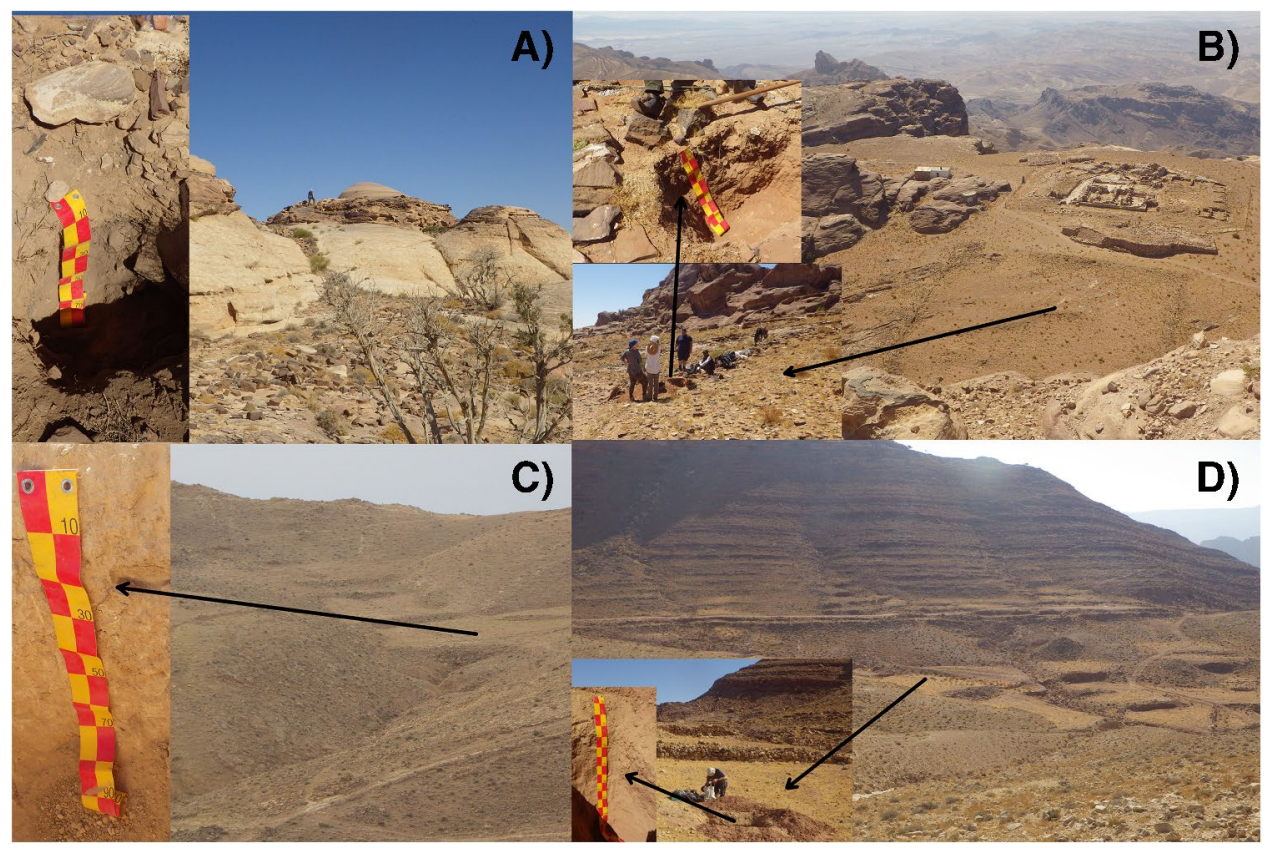

Fig. 3 Profiles sampled in the Petra region in Southern Jordan. (A) A paleosol below the unexcavated pre-pottery Neolithic site of Abu Suwwan (the site is the stone scatter in front). (B) A profile in the probable monastery garden on Jabal Haroun. Note the rectangular wall remains below the ruin of the monastery, which apparently surrounded the garden. The stone pile between the monastery ruin and the rectangular enclosure is excavation debris. (C) A profile on the

\section{Results}

Substantial analytical data was gathered which is only partly presented here, but is mostly summarized in figures or citations of earlier publications. Full results of grain size analysis are given in Table A1 in the Appendix, and full results of total element analysis by XRF are presented in Table A2 in the Appendix. Sample numbers and classifications of deposit types used for statistical modeling are provided in Table A3 in the Appendix. Results of the cistern fill on Umm el-Biyara are not presented as the complex stratigraphy made interpretation difficult with regard to the purposes of this publication, but the site is described as representative example of the problems connected with post-abandonment cistern fills.

\section{Soil structures}

Sediment properties and ages of the studied profiles are summarized in Fig. 6 (northern Negev) and Fig. 7 (Petra region). All hilltop ruin soils were characterized by vesicular layers as well as crusts and clast pavements (Fig. 8). In contrast, vesicular horizons were not present in terrace soils, cistern sediments, or natural reference soils.

Some terrace sections in the Negev showed banded layers in parts of the profile, apparently representing sheet flow runoff-collecting terraces on dolomitic limestone and (D) a profile on the runoff-collecting terraces on sandstone. Note that the parallel lines on the steep sandstone slope in the background partly represent geological layers, and partly remains of ancient terraces. The tape measure is in cm. Figure re-published from Lucke et al. 2019b (Figure $\mathrm{A} 2$ ), creative commons license $\mathrm{CC}-\mathrm{BY}$

sediments deposited during flood events when terraces were not plowed (see Fig. 6: Terrace 3 (western wadi), 10-50-cm depth). Such banded layers were absent in the sampled terraces in Jordan, but could have been erased by land use as these terraces are occasionally plowed by Bedouins until present day.

\section{Sedimentation ages and deposition rates}

In the cistern fill of Umm el-Biyara, the presence of old, unbleached quartz grains from weathering rock of the surrounding sandstone hampered OSL dating. However, the cleanout mound next to the open cistern in the Negev proved more promising for dating. Although it was partly affected by bioturbation of large mammals (probably porcupines), sediments could be dated and represent aeolian-fluvial deposition during the period of cistern use in the Byzantine and early Islamic periods (Lucke et al. 2019b).

Most of the hilltop ruin and terrace profiles could well be dated by OSL and ${ }^{14} \mathrm{C}$, and ages were in agreement with the associated diagnostic archaeological material (see Figs. 6 and 7). However, it seems likely that some of these records do not continue until present day as some hilltop ruin wall remains completely filled with sediments. Similarly, the studied terraces walls were completely buried 


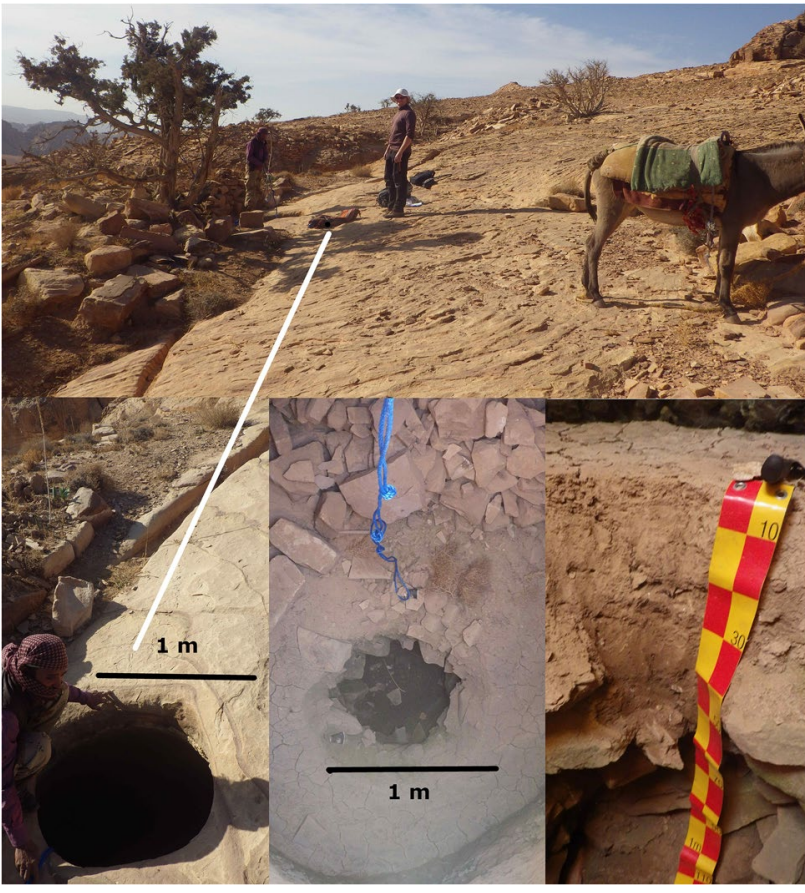

Fig. 4 Picture collage showing sampling of the underground, rock-cut cistern on the mountain of Umm el-Biyara near Petra. Water was collected on the rock surface and channeled towards the cistern opening (images on top and lower left corner, persons and donkey give scale). Access to the 200 -cm-thick sediment fill was possible only by rope (image in bottom center, looking down from cistern opening, excavated profile pit in the middle of the image). The profile revealed a complex, disturbed stratigraphy (bottom right, marks on meter tape represent $10 \mathrm{~cm}$ ), apparently due to repeated (and incomplete) cleaning efforts interrupted by periods of garbage disposal

by sediments and thus probably largely ceased to harvest aeolian sediments after their burial. However, some structures are characterized by wall remains still higher than their sediment fill: the circular hilltop ruin (central wadi) in the northern Negev and the Jabal Farasha and Monastery garden hilltop ruins near Petra. Based on the ages available from these sites, it was possible to estimate mean annual sedimentation rates: $\sim 0.14 \mathrm{~mm}$ were found in the circular hilltop ruin (central wadi) in the northern Negev and in the Jabal Farasha hilltop ruin in the Petra region, which are located on isolated hilltops (Lucke et al. $2019 b)$. These rates are in good agreement with values from current dust collection in standard dry marble collectors (Lucke et al. 2019b; Kidron et al. 2014). However, proximity to rock cliffs hosting active tafoni in the Petra region, given at the monastery garden and a close collector of current dust, is connected with doubled deposition rates of $\sim 0.29 \mathrm{~mm}$ per year (Lucke et al. 2019a, b). As well, a significantly increased sand fraction could be observed, probably a contribution from the tafoni of the sandstone rock cliffs (Fig. 9).
Deposition amounts in archaeological hilltop ruin soils thus exceed Pleistocene sedimentation rates in natural hilltop soils in the southern Negev, which were calculated as 0.02-0.058 mm per year (Crouvi et al. 2009). In terraces, sedimentation rates vary strongly, but are not connected to catchment size or bedrock (Lucke et al. 2019b). They probably depend on the situation and functioning of the runoff irrigation system. Deposition rates of the cistern cleanout were off-scale, and cannot be calculated as average sedimentation rates due to probably highly erratic cleaning activities.

\section{Substrate properties}

Substrates of the sediments in archaeological structures in the northern Negev consist of calcareous silt loams (see Fig. 6), which are very similar to loessial paleosols and current dust samples. Sand fractions (if present) are dominated by fine sand (Lucke et al. 2019b and Table A1 in the Appendix). Fluvial catchment sizes or bedrocks show no connection with terrace sediment properties, but some terraces and the cistern cleanout samples were characterized by slightly elevated clay contents, which is discussed below (Lucke et al. $2019 \mathrm{~b}$ and Table A1 in the Appendix).

The sediments covering archaeological structures include material from "recycled" loessial paleosols and local soils, which agrees with other recent studies that found re-deposition of paleosol material in current dust (Shalom et al. 2020). Such contributions from paleosols are difficult to be recognized due to the similarity of natural loess soils, dust samples, and soils covering archaeological structures. In case of our study, they could, for example, be traced in the circular hilltop ruin in the central wadi at Horvat Haluqim in the Negev due to elevated $\mathrm{P}_{2} \mathrm{O}_{5}$ contents. This hilltop ruin is located close to an abandoned archaeological site on the valley slopes that was identified as a local dust source contributing material to the sediments covering the hilltop ruin (Lucke et al. 2019b and Table A2).

In the Petra region, substrates of soils in archaeological structures consist of calcareous loams. They are characterized by higher shares of sand than in the Negev, in particular medium sand, which was found to be derived from the surrounding sandstones whose grain size distribution is dominated by medium sand (Lucke et al. 2019b). Similarly, proximity to outcrops of dolomitic limestone came along with elevated $\mathrm{Mg}$ contents. As in the Negev, fluvial catchment sizes or bedrocks in the Petra region seem to play no role for terrace sediment properties, but some of the terrace samples are characterized by elevated clay contents (Lucke et al. 2019b).

Natural soils and paleosols in the Petra region consist of loamy sand, meaning that they contain more sand than the soils covering archaeological structures, and largely represent disintegrated sandstone (Lucke and Bäumler 2007). 


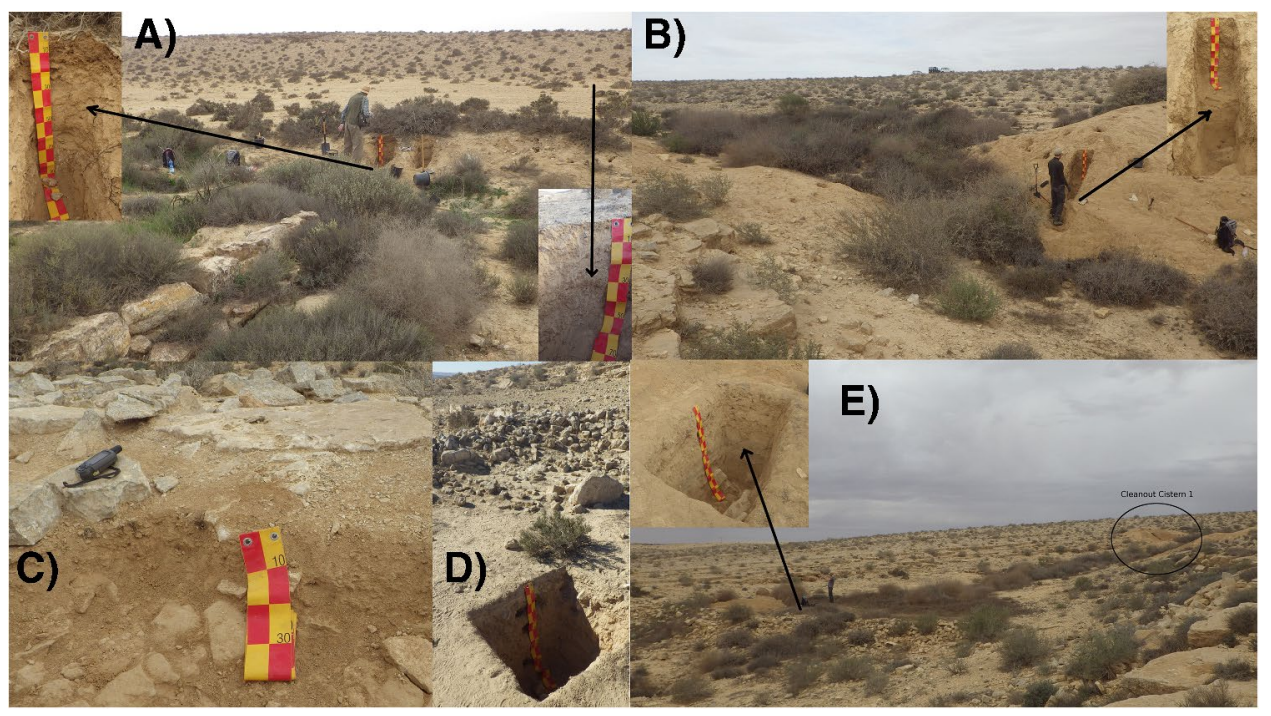

Fig. 5 Profiles sampled in the northern Negev in Israel. (A) A profile of the runoff-collecting terrace in a tributary of Nahal HaRo'a (left) and a loessial paleosol in the nearby colluvial-aeolian apron (right). (B) A profile excavated in the sediment pile cleaned out from Cistern 1 in the western wadi of Horvat Haluqim (to the left-vegetation obscures the structure, but marks the area where water is currently gathering). (C) A soil in the hilltop tumulus grave structure at the western wadi of Horvat Haluqim. (D) A profile in the hilltop ruin at the central wadi of Horvat Haluqim. (E) A profile excavated in Terrace 3 at the western wadi. Vegetation shows where moisture is still gathering today. Note the sediment cleanout pile of Cistern 1 to the right: water was first channeled into open cisterns in the uppermost part of the valleys, and when these were filled, it ran to the fields below. The tape measure is in $\mathrm{cm}$. Figure re-published from Lucke et al. 2019b (Figure A3), creative commons license CC-BY

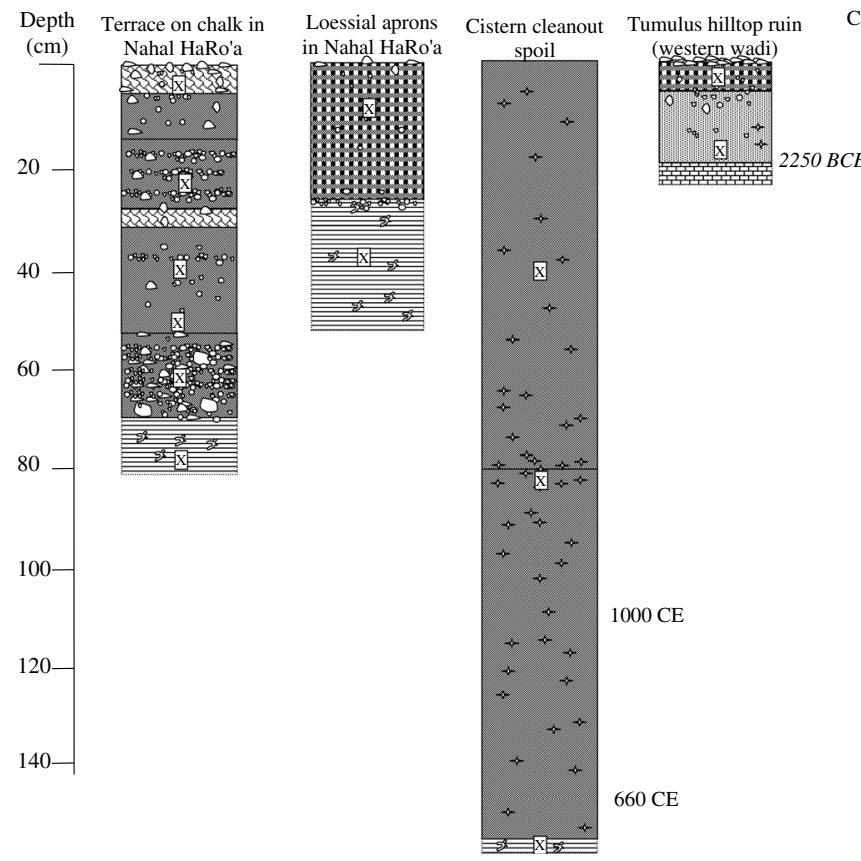

Fig. 6 Schematic drawings of the profiles in the northern Negev showing available ages (OSL ages in normal letters, ages from archaeological context in italics, and ${ }^{14} \mathrm{C}$ ages in bold and italics) as

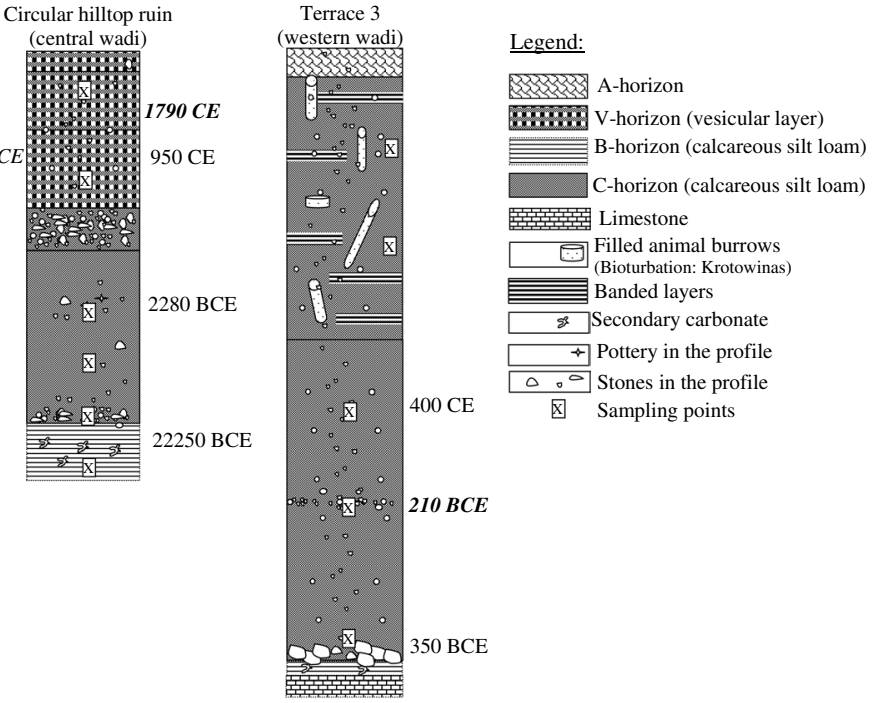

Diagnostic horizons, substrates, and sampling points of soils in archaeological structures in the Negev

well as diagnostic horizons, sampling points, and substrates. Figure under creative commons license, re-published from Lucke et al. (2019b, Fig. 4, p. 11, CC BY), modified 


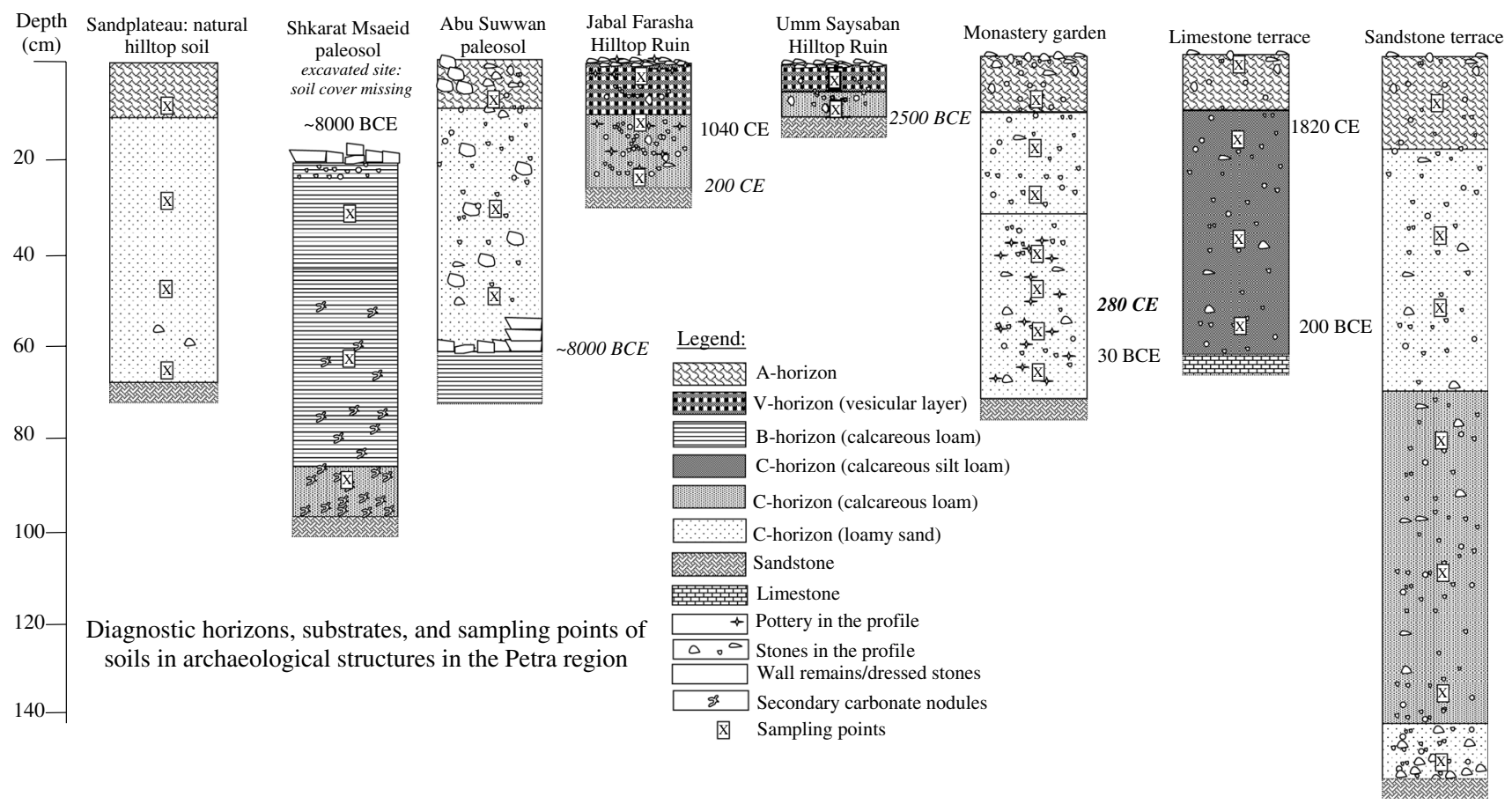

Fig. 7 Schematic drawings of the profiles in the Petra region showing available ages (OSL ages in normal letters, ages from archaeological context in italics, and ${ }^{14} \mathrm{C}$ ages in bold and italics) as well as diagnos- tic horizons, sampling points, and substrates. Figure under creative commons license, re-published from Lucke et al. (2019b, Fig. 3, p. 9 , CC BY), modified
Fig. 8 Collage showing clast pavements, surface crusts, and vesicular layers of the Jabal Farasha hilltop ruin near Petra. Pen gives scale. Top left: surface clast pavement. Bottom left: After careful removal of clasts, the surface crust and vesicular aggregates are visible. Right: close-up showing the upper part of the sediment profile

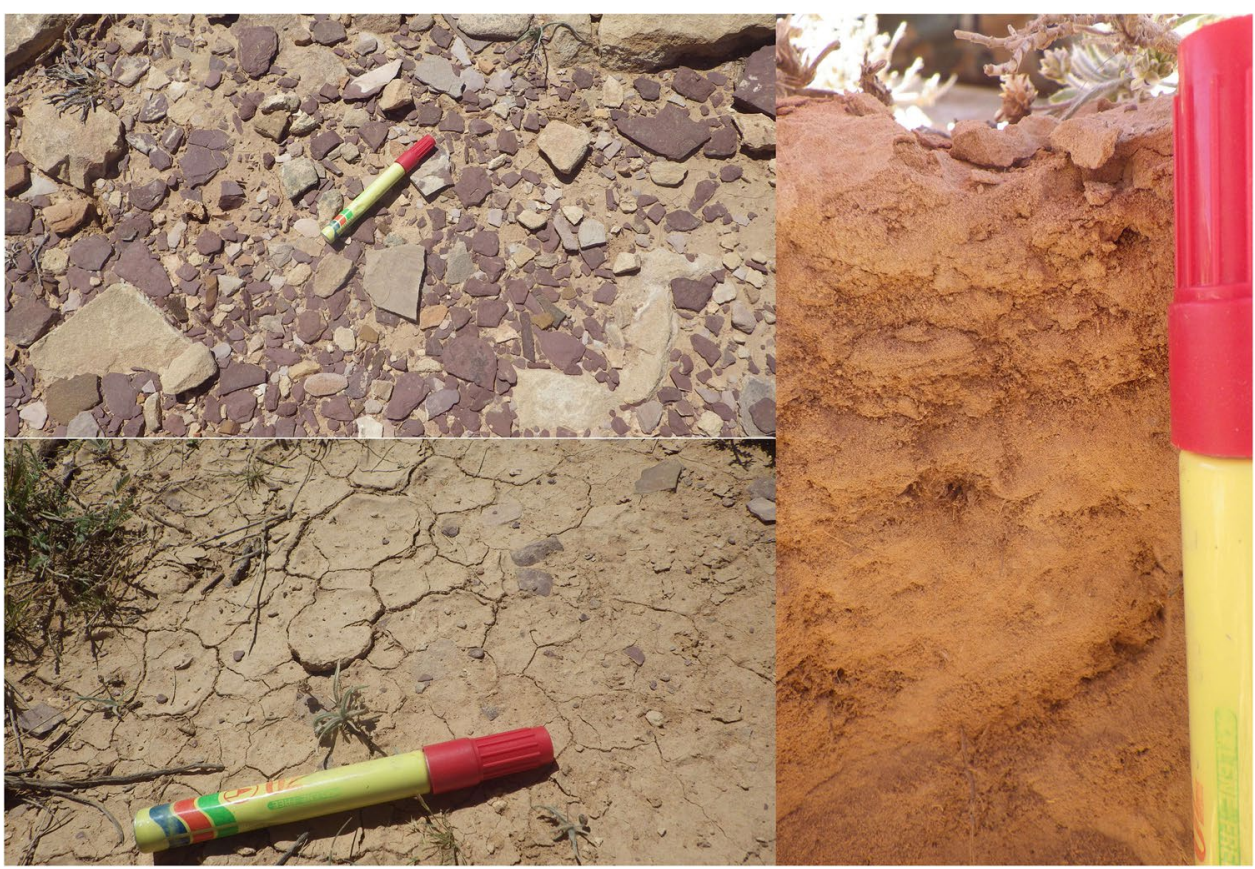

Dust samples in the Petra region show textures of loamy sand, too. Similar to results from archaeological hilltop structures, proximity of dust collectors to rock cliffs with active tafoni leads to higher sand contents (in particular of medium sand). However, dust samples that were associated with precipitation consist of calcareous loam, characterized by higher shares of silt, of $\mathrm{CaCO}_{3}$, and of major and trace elements than dry dust samples (Lucke et al. 2019a, b).

The largest amount of collected dust sample was associated with precipitation, in particular one snow event. 


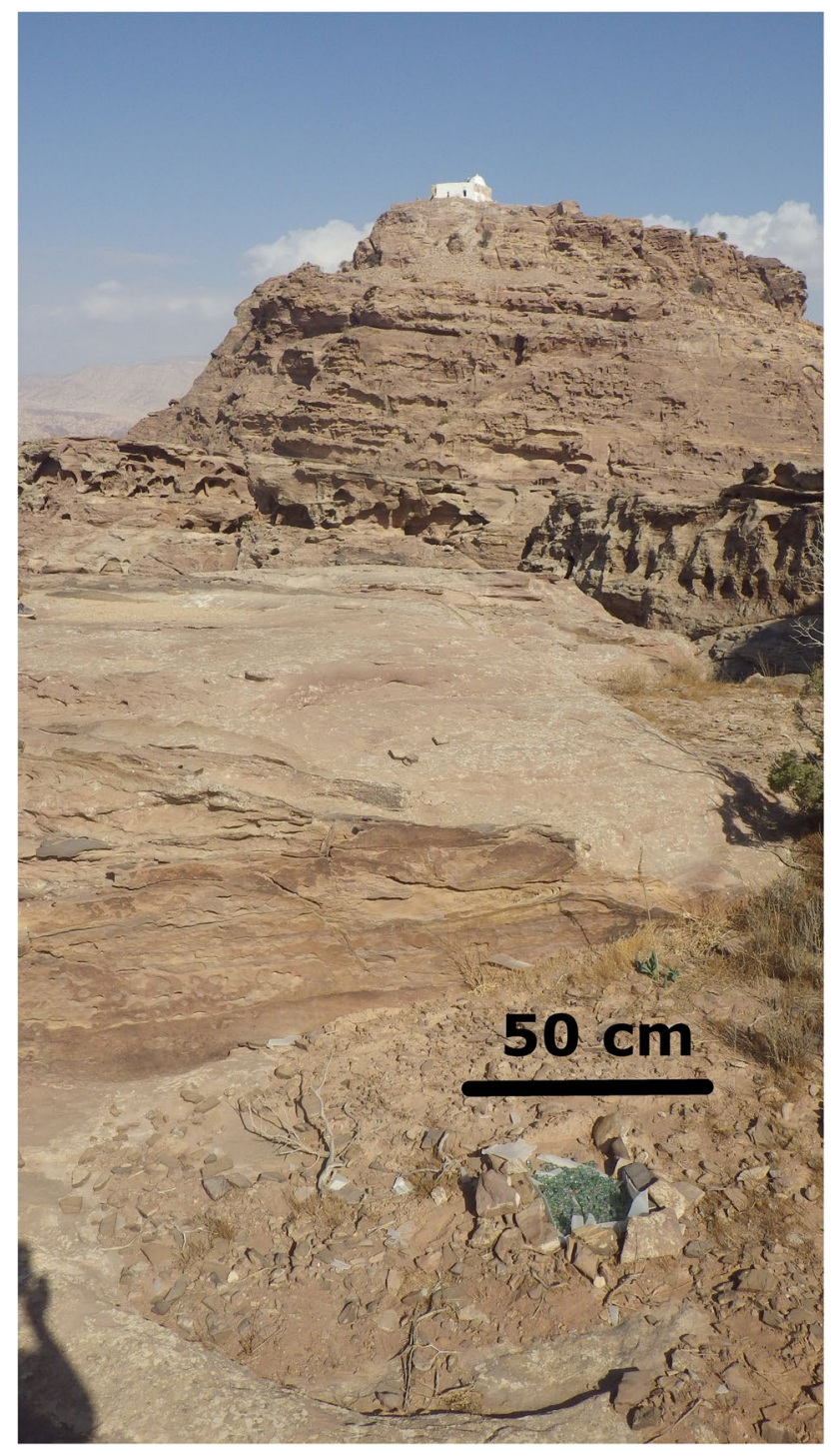

Fig. 9 Rock cliffs overlooking the ruins of the monastery on Jabal Haroun. The white building in the background on the mountain summit is the Islamic pilgrimage shrine of Jabal Haroun. Note the tafoni at rocks and the dust collector in front, which had to be hidden on the cliff in order to protect the glass marbles from children

Samples associated with precipitation showed higher shares of calcareous silt. As well, larger distance from rock cliffs in the Petra region seems connected with higher contents of calcareous silt in current dust samples. Wind speed and directions, as far as data was available from nearby meteorological stations, seemed not to have played a role for dust composition and deposition (Lucke et al. 2019b), but the recorded variance of wind speeds was relatively small. One exceptional large dust sample not associated with precipitation may have been connected with a dust devil (Lucke et al. 2019b).
In situ weathering due to pedogenesis in all sampled profiles in both study regions was found to be minimal. This includes Negev paleosols bearing secondary carbonates, suggesting that dissolution and re-precipitation of this mineral was connected with rather short episode(s) of elevated moisture not sufficient to lead to (iron) oxidation or silicate weathering, which means that slightly higher clay contents as observed in some cistern and terrace samples are apparently not connected with in situ weathering due pedogenesis (Lucke et al. 2019b).

\section{Statistical modeling}

Principal component analysis on geochemical data was performed (see Appendix: Table A2 and Table A4 for sample numbering), allowing to group samples according to their chemical similarity (Fig. 10). This analysis suggests that the type of ruin matters less for the geochemical composition of sediments in archaeological structures. In the Petra region, it depends more on proximity to aeolian contributions from weathered rocks. Most samples from archaeological structures in both investigation regions cluster in the center of the graph, whereas rocks are located at the fringes. Negev dust samples cluster close to each other, and cannot well be separated from Negev archaeological sediments, while Petra dust samples scatter between groups of archaeological sediments and rocks. Dust samples associated with precipitation in the Petra region are more similar to sediments in archaeological structures.

Statistical modeling of deposit types (see Table A3, "type") used the full available analytical dataset and applied the random forest approach. It had an overall classification error of $10.71 \%$, which was mainly connected with specific samples. For example, a Turonian paleosol exposed in the study area in northern Negev was sampled as potential dust source and counted as "Negev rock," but its properties proved statistically similar to "terrace soil" (Lucke et al. 2019b). The model suggests that sediments in archaeological structures represent a specific deposit type, regardless of study region or type of ruin. The different types of ruins could also be modeled as sub-classes, with unchanged error. Rock and dust samples, as well as reference soils, were modeled as clearly distinguished deposit types. It can be summarized that sediments in archaeological structures were characterized by grain size distributions including most particle size classes and rather high concentrations of various major and trace elements (Lucke et al. 2019b). 


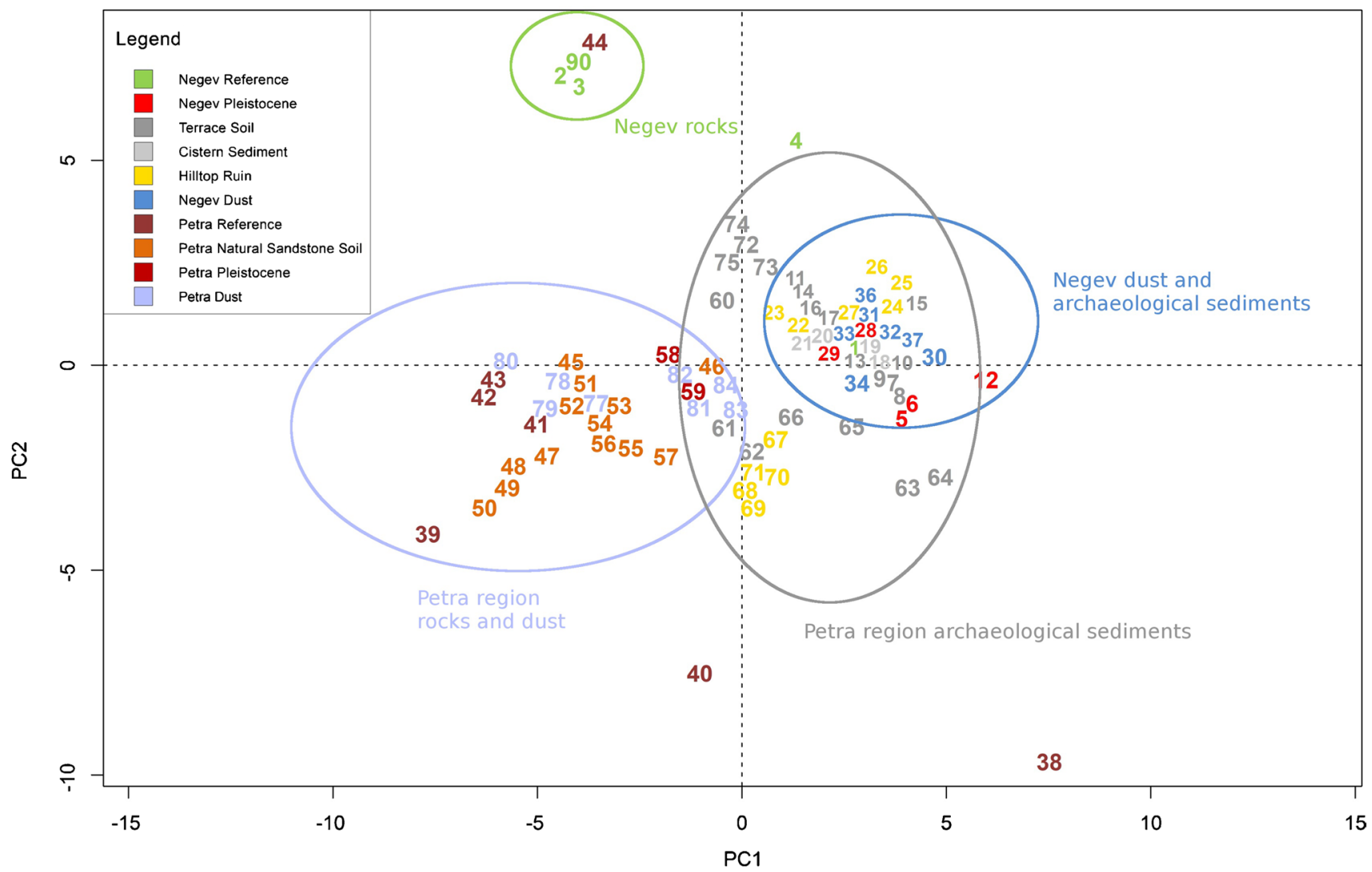

Fig. 10 Principal component analysis of geochemical properties of the studies samples (see Table A3 for detailed sample designation). Circles mark the rough distribution of sample types. Figure re-pub- lished from Lucke et al. 2019b, Fig. 13, modified, under creative commons license CC-BY

Table 3 Expected deposition processes, sediment sources, and disturbances in the different studied archaeological structures

\begin{tabular}{|c|c|c|c|c|}
\hline Archive type & $\begin{array}{l}\text { Dominating deposi- } \\
\text { tion processes }\end{array}$ & Main sediment sources & Remobilization likelihood & Post-deposition disturbances \\
\hline Hilltop ruins & Aeolian & $\begin{array}{l}\text { Dust and archaeological mate- } \\
\text { rial }\end{array}$ & Limited & Animal burrows \\
\hline Cisterns & Aeolian and fluvial & Dust and fluvial sediments & None & None \\
\hline Runoff-irrigated terraces & Fluvial and aeolian & $\begin{array}{l}\text { Fluvial sediments, dust, man- } \\
\text { made deposits }\end{array}$ & High; possible source of dust & $\begin{array}{l}\text { Plowing, animals, re-building } \\
\text { of walls }\end{array}$ \\
\hline
\end{tabular}

Table 4 Measured deposition processes, sediment sources, and disturbances in the different studied archaeological structures

\begin{tabular}{lllll}
\hline Archive type & Dominating deposition processes & Main sediment sources & Remobilization evidence & Post-deposition disturbances \\
\hline Hilltop ruins & Aeolian & Dust & None & Roots \\
Cisterns & Aeolian (with runoff), garbage & Dust, garbage, weather- & Cleaning/ excavation & Repeated cleaning and \\
& dumping, weathering of walls & ing rock walls & & garbage deposition \\
Runoff-irrigated terraces & Aeolian (amplified by runoff) & Dust & None & Plowing, animal burrows \\
\hline
\end{tabular}




\section{Discussion}

\section{Suitability and reliability of the different studied types of archaeological structures}

When starting our investigation, we expected that the individual ruins would store sediments in different ways, depending of the types of ruin, and that the dominating deposition processes would vary accordingly, too (Table 3 ). Cisterns were assumed to provide the least disturbed dust record, bioturbation was expected in hilltop ruin sediments, and terrace substrates were presumed to comprise significant slope-wash from local rocks and soils.

Our results, however, show that sediments in all structures are of aeolian origin (Table 4). Hilltop ruin sediments seem characterized by rather constant deposition rates (at least until filled completely with sediment), clear stratigraphy, and have no evidence of disturbances. Terrace sediments have more variable deposition rates, but stratigraphies were clear, despite occasional bioturbation. It should be mentioned that sampling avoided proximity to walls, as these may act as entry points of bioturbating animals. Cistern sediments proved the most challenging archive. Due to repeated reuse, garbage disposal, (partial) cleaning, and weathering of walls of rock-cut underground cisterns, they were found to be the in fact least promising type of ruin.

This does not mean that cisterns are generally not suited as aeolian sediment archives. Post-abandonment fills of open cisterns, which we did not investigate in this study, might provide a better sediment record than rock-cut underground cisterns, as the open cistern may be less affected by garbage disposal and the contribution from weathering rock walls is smaller. In addition, sediments in open cisterns will be fully exposed to light, which should make dating by optical stimulated luminescence (OSL) possible. However, surveys and interviews with Bedouins still operating cisterns (often re-used ancient ones) in our study regions showed that most water storage installations were re-used rather recently. In order to prevent the establishment of parasites, actually used cisterns are cleaned every second of third year. Therefore, it seems likely that sediments that accumulated during cistern use can be found mainly in cleanout piles (Lucke et al. 2019b), whereas the material in disused cisterns represents post-abandonment sedimentation (Junge et al. 2018).

\section{Suitability of archaeological structures as archives of aeolian sedimentation}

The presence of vesicular layers clearly demonstrates the formation of archaeological soils on hilltop ruins by aeolian deposition processes. Disturbances were minimal. Only in one case, debris from ruined buildings affected sediment properties, which could however easily be identified (Lucke et al. 2019a).

Vesicular layers were not observed in terraces and cistern sediments, and it seems obvious that such structures could not develop due to fluvial redistribution. However, the material in terraces and cisterns is derived from fluvially re-distributed aeolian dust. This can be deduced from the similarity of the substrates to those of soils covering hilltop ruins. Fluvial processes such as runoff irrigation of the terraces seem enhance the speed of sediment aggradation, but not affect the physico-chemical composition of the substrates. Therefore, runoff mainly re-distributes material in the archaeological ruins, whereas the primary deposition and composition of all sediments is dominated by aeolian processes and sources.

The role of archaeological ruins as dust traps is further demonstrated by statistical modeling of the random forest approach. Substrates of all archaeological structures proved of similar type in both investigation regions, which is counter-intuitive as sand contents in the Petra region are generally higher. Despite of the difference of geological setting, the sediments covering all types of archaeological structures could statistically be modeled with high confidence as one characteristic substrate in both investigation regions (Lucke et al. 2019b).

Natural soils and dust samples were, in contrast, modeled as different substrate types, and proved different and specific for each investigation region. That leaves us with a challenge: although the soils covering archaeological structures are derived from aeolian sediments, and similar in both regions, their substrate composition differs from associated natural soils and samples of current settling dust.

\section{Efficiency of various dust collector types}

It is important to note that current dust gathered in collectors is not identical with the material moving through the atmosphere: different types of collectors catch different parts of this material (Goossens and Offer 1994, 2000; Sow et al. 2006). Tested dust collectors did, in this context, not completely collect the material moving through the air, but rather a small fraction (of $\sim 20 \%$ in dry marble collectors, depending on wind speed) (Sow et al. 2006). Dry marble collectors as used in our study are in this context known as susceptible to re-mobilization of material, in particular the clay fraction which is higher in wet samplers (Goossens and Offer 1994; Kidron et al. 2014). As standing water is sometimes present after rainstorms in the sampled terraces, and was connected with primary sedimentation of the cistern cleanout, this could explain the slightly elevated clay contents of terrace and cistern cleanout samples (Lucke et al. 2019b). 
Dry marble dust collectors seem to collect quite similar amounts of dust as archaeological structures, indicated by the very similar sedimentation rates, which points to a similar effect of marbles and stone debris with regard to the settling of dust. However, the difference of the collected material needs to be explained.

\section{Sediment fixation processes in archaeological structures}

As indicated by the omnipresence of vesicular layers and clast covers in hilltop ruins, dust accretion in these archaeological structures could be similar to that in "desert pavements" (Lucke et al. 2019a). While wall remains provide wind shadow and minimize water erosion, the rough surfaces of clast covers could fix dust while remaining on top of the sediments and forming a "pavement." Stones and pottery are present as dense cover on nearly all studied hilltop ruin soils and might, similar to desert pavements, trap aeolian dustfall (McFadden et al. 1987, 1998). That would make the process similar to dust accretion below desert pavements. Here, it should be mentioned that the formation of vesicular layers, which are characteristic for desert pavements, was shown by Turk (2012) to result from crust-sealed surfaces trapping air which expands under water infiltration. It should be noted that surface-sealing crusts were present in all studied hilltop ruins, too.

Although it was not possible to determine whether these crusts were of physical or biological type, it must be noted that biological crusts were found to fix dust of silt and clay size, but not larger grains (Danin and Ganor 1991; Wieler et al. 2019; Kidron et al. 2020). Higher silt contents in archaeological soils in the Petra region as compared to current dust samples and natural soils might therefore be explained with the presence of such crusts. In contrast, the the dust-fixing effect of biological crusts in the Negev might not be visible due to scarcity of sand in that region.

\section{Role of precipitation}

The composition of aeolian sediments depends on their position in the atmosphere: suspended dust in the high atmosphere, mainly consisting of clay-sized particles, is omnipresent and very homogeneous (Kalderon-Asael et al. 2009; Bodenheimer et al. 2019). Settling dust, however, is of different composition and partly depends on the direction and intensity of storms (Singer et al. 2003, 2004). It seems possible that larger grains which are mobilized during intensive storm events might "harvest" clay coatings from suspended dust in higher altitudes, in particular under wet conditions (Lucke et al. 2019b).

The dust samples that were in our study sampled during precipitation, in particular in case of snow, are larger and of finer texture. Chemically, they are depleted in $\mathrm{SiO}_{2}$, but enriched by $\mathrm{CaCO}_{3}$ and all other major and trace elements (Lucke et al. 2019b). These elements and elevated magnetic susceptibilities and concentrations of extractable iron corresponded to higher calcareous silt fractions.

Precipitation might therefore have a threefold effect on aeolian sedimentation in the southern Levant:

(i) It could enhance the "harvesting" of suspended dust as clay coatings of silt grains.

(ii) Foster sediment fixation by crust development due to moist surfaces (by precipitating physical crusts rich in secondary $\mathrm{CaCO}_{3}$, and/or due to well-nourished biological crusts (Wieler et al. 2019; Kidron et al. 2020).

(iii) Reduce the contribution of local dust emissions due to wetted surfaces.

\section{Role of dust sources}

One basic premise of most studies dealing with the loessial paleosols in the Negev is that primary (hilltop) terrestrial sediments represent more or less directly material from remote sources that was moved through the atmosphere (e.g., Crouvi et al. 2008, 2009). Formation of Negev loess has so far been approached from the supply side, based on the premise that its genesis depended primarily on generation and transport of sufficient silt through the atmosphere (Smalley et al. 2019; Lancaster 2020).

With regard to the Negev, abrasion of silt-sized quartz grains from moving Sinai sand dunes has been proposed as main dust-producing process, leading to downwind formation of the loessial paleosols during periods of dune activity (Enzel et al. 2010). However, Negev loess formation was found to significantly pre-date dune activity periods (Roskin et al. 2011a, b; Roskin 2021). In addition, various other processes such as fluvial comminution, salt weathering, frost shattering, insolation weathering, volcanism, and deep weathering of saprolite can produce silt and develop a range of local dust sources (Wright 2007; Ojha et al. 2018). Fluvial comminution in turbulent flow, such as during the frequent flash floods in the southern Levant, was found the most effective short-time process of silt production (Wright et al. 1998). This suggests that local sources such as fans of wadis may provide significant amounts of silt-sized sediments.

Our results from Holocene aeolian sediments in archaeological structures of the southern Levant indicate that the question of Negev loess might have been approached from the wrong direction: it could less be a matter of dust supply, but more of dust fixation processes. There is no lack of silt-sized dust moving through the air in in the 
southern Levant, but this dust rarely settles to form soils. Only when structures comparable to dust collectors prevent re-mobilization of the aeolian sediments, they stay. Similar results of local loess re-distribution were found at the southern slopes of the Eastern Himalayas (Caspari et al. 2009).

Therefore, formation of Pleistocene paleosols in the Negev may mainly have resulted from enhanced dust fixation-probably due to enhanced vegetation cover and/or more widespread biological crusts, and possibly more frequent occurrence of snow.

\section{Conclusions}

Aeolian sediments in archaeological structures and current dust traps near Petra in southern Jordan and in the northern Negev in Israel indicate that local dust sources, surface crusts, and clast pavements, as well as the presence of vegetation, play key roles for dust deposition processes in these regions. This suggests that aeolian sedimentation may less be dominated by dust supply (in particular from remote sources), but that dust fixation mechanisms may play far larger roles than previously assumed. Archaeological ruins resemble the effects of current dust collectors, storing material that would otherwise be re-mobilized. Dust settling in archaeological structures is not identical with that collected in dry marble dust collectors: this is due to different fixation mechanisms, mirroring the changing dust samples of various collector types. It is likely that wind shadow effects, surface roughness, and the presence of (physical or biological) crusts in archaeological ruins play key roles for dust fixation, and explain why sediments in archaeological ruins in the Negev and the Petra region can be statistically modeled as one characteristic sediment type-despite different geologies and contributions from local sources.

Due to the prevailing, easily erodible rocks (indicated by a multitude of active tafoni), local sources from geological outcrops contributed significant material in the Petra region. Contributions from hard limestones in the Negev, in contrast, are minimal. However, eroding soils and paleosols in the Negev are partly recycled: mobilized into the atmosphere and then re-deposited in archaeological structures. Precipitation, in particular snow, seems to enhance dust accretion. Due to a prevailing focus on material from remote sources and the premise that variations of aeolian records reflect changing sediment supply, the importance of fixation processes and local sources for dust deposition in the southern Levant might have been underestimated. It seems possible that not changes of dust supply, but local conditions with regard to presence or absence of dust-fixing vegetation and crusts, as well as changing precipitation patterns associated with dustfall, governed changes of the type and amount of settling aeolian sediments.

Supplementary Information The online version contains supplementary material available at https://doi.org/10.1007/s12517-021-08884-5.

Acknowledgements We thank the three unknown reviewers whose comments helped to improve the manuscript.

Author contribution All authors contributed to the study conception and design. Material preparation, data collection, and analysis were performed by Bernhard Lucke. The first draft of the manuscript was written by Bernhard Lucke, and all authors commented on previous versions of the manuscript. All authors read and approved the final manuscript.

Funding Open Access funding enabled and organized by Projekt DEAL. This research was funded by the German Research Foundation (DFG, grant no. LU1552/2-1) and the Third Conference of the Arabian Journal of Geosciences (CAJG) where the respective presentation received the best paper award in track 9 (Geomorphology, Geography, Soil Science, Glaciology, Geoarchaeology, Geoheritage).

Data availability The data, unless already published, is available from the authors.

Code availability Not applicable.

\section{Declarations}

Conflict of interest The authors declare that they have no competing interests.

Open Access This article is licensed under a Creative Commons Attribution 4.0 International License, which permits use, sharing, adaptation, distribution and reproduction in any medium or format, as long as you give appropriate credit to the original author(s) and the source, provide a link to the Creative Commons licence, and indicate if changes were made. The images or other third party material in this article are included in the article's Creative Commons licence, unless indicated otherwise in a credit line to the material. If material is not included in the article's Creative Commons licence and your intended use is not permitted by statutory regulation or exceeds the permitted use, you will need to obtain permission directly from the copyright holder. To view a copy of this licence, visit http://creativecommons.org/licenses/by/4.0/.

\section{References}

Adams SM, Soreghan GS (2020) A test of the efficacy of sand saltation for silt production: implications for the interpretation of loess. Geology 48(11):1105-1109

Amit R, Enzel Y, Crouvi O (2021) Quaternary influx of proximal coarse-grained dust altered circum-Mediterranean soil productivity and impacted early human culture. Geology 49(1):61-65

Avni Y, Porat N, Plakht J, Avni G (2006) Geomorphologic changes leading to natural desertification processes versus anthropogenic land conservation in an arid environment, the Negev Highlands, Israel. Geomorphology 82:177-200. https://doi.org/10.1016/j. geomorph.2006.05.002 
Avni Y, Weiler N (2013) Geological map of Israel 1:50,000 Sede Boqer Sheet 18-IV, Geological Survey of Israel, Jerusalem

Avni Y, Avni G, Porat N (2019) A review of the rise and fall of ancient desert runoff agriculture in the Negev Highlands-a model for the southern Levant deserts. J Arid Environ. https://doi.org/10.1016/j. jaridenv.2019.01.010

Barjous MO (2003) The geology or Petra and Wadi Lahyana area, Map Sheets No. 3050-I and 3050-IV. Bulletin 56, Hashemite Kingdom of Jordan, Natural Resources Authority, Geology Directorate, Geological Mapping Division, Amman

Bender F (1974) Geology of Jordan. Gebrüder Borntraeger: Berlin, Germany; ISBN 978-3443117078

Bodenheimer S, Lensky IM, Dayan U (2019) Characterization of Eastern Mediterranean dust storms by area of origin; North Africa vs. Arabian Peninsula. Atmos Environ 198:158-165. https://doi.org/ 10.1016/j.atmosenv.2018.10.034

Bowman D, Karnieli A, Issar A, Bruins H-J (1986) Residual colluvioaeolian aprons in the Negev highlands (Israel) as a palaeo-climatic indicator. Palaeogeogr Palaeoclimatol Palaeoecol 56:89-101. https://doi.org/10.1016/0031-0182(86)90109-4

Bruins HJ (1976) The origin, nature and stratigraphy of paleosols in the loessial deposits of the NW-Negev (Netivot, Israel). M.Sc. thesis, The Hebrew University, Jerusalem

Bruins HJ, Yaalon DH (1979) Stratigraphy of the Netivot section in the desert loess of the Negev (Israel). Acta Geol. Acad. Sci. Hung 22(1-4):161-169

Bruins HJ, Yaalon DH (1992) Parallel advance of slopes in aeolian loess deposits of the northern Negev, Israel. Isr J Earth Sci 41:189-199

Bruins H, Jongmans A (2012) Micromorphology of ancient agricultural Terraces in the Negev Desert, Horvat Haluqim (Israel). In Proceedings of the 14th International Working Meeting on Soil Micromorphology - Lleida 8-14 July 2012; Poch RM, Casamitjana M, Francis ML (Eds.); Departament de Medi Ambient i Ciències del Sòl (UdL): Lleida, Spain, pp. 292-295, ISBN: 978-84-615-9132-9

Caspari Th, Bäumler R, Norbu C, Tshering K, Baillie I (2009) Soil formation in Phobjikha Valley, Central Bhutan with special regard to the redistribution of loessic sediments. J Asian Earth Sci 34:403-417

Cordova C (2007) Millenial landscape change in Jordan. University of Arizona Press: Tucson, USA, ISBN 978-0816525546

Crouvi O, Amit R, Enzel Y, Porat N, Sandler A (2008) Sand dunes as a major proximal dust source for late Pleistocene loess in the Negev Desert, Israel. Quatern Res 70(2):275-282. https://doi. org/10.1016/j.yqres.2008.04.011

Crouvi O, Amit R, Enzel Y, Gillespie AR, McDonald EV (2009) The significance of studying primary hilltop, aeolian loess: an example from the Negev desert, Israel. J Geophys Res 114:1-16. https://doi.org/10.1029/2008JF001083

Danin A, Ganor E (1991) Trapping of airborne dust by Mosses in the Negev Desert, Israel. Earth Surf Proc Land 16:153-162

Enzel Y, Amit R, Crouvi O, Porat N (2010) Abrasion-derived sediments under intensified winds at the latest Pleistocene leading edge of the advancing Sinai-Negev erg. Quatern Res 74(1):121131. https://doi.org/10.1016/j.yqres.2010.04.002

Erickson-Gini T, Porat N (2018) Sheluhat Qadesh Barne'a. Hadashot Arkheologiyot: excavations and surveys in Israel

Faershtein G, Porat N, Avni Y, Matmon A (2016) Aggradation-incision transition in arid environments at the end of the Pleistocene: an example from the Negev Highlands, southern Israel. Geomorphology 253:289-304. https://doi.org/10.1016/j.geomo rph.2015.10.017

Gerson R, Amit R (1987) Rates and modes of dust accretion and deposition in an arid region: the Negev, Israel. Geol Soc Spec Publ 35:157-169
Goldberg P (1986) Late quaternary environmental history of the southern Levant. Geoarchaeology 1(3):225-244. https://doi.org/ 10.1002/gea.3340010301

Goodfriend GA, Magaritz M (1988) Palaeosols and late Pleistocene rainfall fluctuations in the Negev Desert. Nature 332(6160): 144

Goossens D, Offer ZY (1994) An evaluation of the efficiency of some eolian dust collectors. Soil Technol 7(1):25-35

Goossens D, Offer ZY (2000) Wind tunnel and field calibration of six aeolian dust samplers. Atmos Environ 34(7):1043-1057

Goudie A (2013) Arid and semi-arid geomorphology. Cambridge University Press, Cambridge

Issar A, Bruins HJ (1983) Special climatological conditions in the deserts of Sinai and the Negev during the latest Pleistocene. Palaeogeogr Palaeoclimatol Palaeoecol 3(43):63-72

Junge A, Lomax J, Shahack-Gross R, Dunseth ZC, Finkelstein I, Fuchs M (2016) OSL Age Determination of archaeological stone structures using trapped aeolian sediments: a case study from the Negev Highlands, Israel. Geoarchaeology 31(6):550 563. https://doi.org/10.1002/gea.21578

Junge A, Lomax J, Shahack-Gross R, Finkelstein I, Fuchs M (2018) Chronology of an ancient water reservoir and the history of human activity in the Negev Highlands, Israel. Geoarchaeology 33(6):695-707. https://doi.org/10.1002/gea.21682

Kalderon-Asael B, Erel Y, Sandler A, Dayan U (2009) Mineralogical and chemical characterization of suspended atmospheric particles over the east Mediterranean based on synoptic-scale circulation patterns. Atmos Environ 43(25):3963-3970

Kidron GJ, Zohar M, Starinsky A (2014) Spatial distribution of dust deposition within a small drainage basin: implications for loess deposits in the Negev Desert. Sedimentology 61: 1908-1922. https://doi.org/10.1111/sed.12121

Kidron GJ, Xiao B, Benenson I (2020) Data variability or paradigm shift? Slow versus fast recovery of biological soil crusts-a review. Sci Total Environ 721:137683

Lancaster N (2020) On the formation of desert loess. Quatern Res 96:105-122

Lucke B, Schmidt M, al-Saad Z, Bens O, Hüttl RF (2005) The abandonment of the decapolis region in Northern Jordan-forced by environmental change? Quaternary International, 135, Special issue: Geochronology and Environmental Reconstruction: a Tribute to Glenn A. Goodfriend, 65-81

Lucke B (2008) Demise of the Decapolis. Past and present desertification in the context of soil development, land use, and climate. Verlag Dr. Müller: Saarbrücken, Germany, ISBN 978-3639006131

Lucke B, Bäumler R (2007) Soils and paleosols at Ba‘ja. Neo-Lithics 02(07):43-50

Lucke B, Ziadat F, Taimeh A (2013) The soils of Jordan. In Atlas of Jordan. History, Territories and Society; Ababsa, M., Ed.; Institut Français du Proche-Orient: Beirut, Lebanon, pp. 72-76

Lucke B, Roskin J, Vanselow K, Bruins H, Abu-Jaber N, Deckers K, Lindauer S, Porat N, Reimer P, Bäumler R, Erickson-Gini T, Kouki P (2019a) Character, rates, and environmental significance of dust accumulation in archaeological hilltop ruins in the southern Levant. MDPI Geosci 9(190):1-60. https://doi.org/10.3390/ geosciences 9040190

Lucke B, Sandler A, Vanselow KA, Bruins HJ, Abu-Jaber N, Bäumler R, Porat N, Kouki P (2019b) Composition of modern dust and holocene aeolian sediments in archaeological structures of the Southern Levant. MDPI Atmos 10:1-84. https://doi.org/10.3390/ atmos 10120762

Lucke B (2021) Quaternary influx of proximal coarse-grained dust altered circum-Mediterranean soil productivity and impacted early human culture: COMMENT. Geology 49(11):e539

McFadden LD, Wells SG, Jercinovich MJ (1987) Influences of eolian and pedogenic processes on the origin and evolution of desert 
pavements. Geology 15(6):504-508. https://doi.org/10.1130/ 0091-7613(1987)15\%3c504:IOEAPP\%3e2.0.CO;2

McFadden LD, McDonald EV, Wells SG, Anderson K, Quade J, Forman SL (1998) The vesicular layer and carbonate collars of desert soils and pavements: formation, age and relation to climate change. Geomorphology 24(2-3):101-145. https://doi.org/ 10.1016/S0169-555X(97)00095-0

Ojha L, Lewis K, Karunatillake S, Schmidt M (2018) The Medusae Fossae Formation as the single largest source of dust on Mars. Nat Commun 9(1):2867

Porat N, Avner U, Holzer A, Shemtov R, Horwitz LK (2013) Fourthmillennium-BC 'leopard traps' from the Negev Desert (Israel). Antiquity 87(337):714-727

Roskin J, Tsoar H, Porat N, Blumberg DG (2011a) Palaeoclimate interpretations of Late Pleistocene vegetated linear dune mobilization episodes: evidence from the northwestern Negev dunefield, Israel. Quat Sci Rev 30(23-24):3364-3380

Roskin J, Porat N, Tsoar H, Blumberg DG, Zander AM (2011b) Age, origin and climatic controls on vegetated linear dunes in the northwestern Negev Desert (Israel). Quatern Sci Rev 30(13-14):1649-1674

Roskin J, Katra I, Blumberg DG (2014) Particle-size fractionation of eolian sand along the Sinai-Negev erg of Egypt and Israel. Bulletin 126(1-2):47-65

Roskin J (2021) Quaternary influx of proximal coarse-grained dust altered circum-Mediterranean soil productivity and impacted early human culture: COMMENT. Geology 49(3):e519-e519

Sandler A (1996) A turonian subaerial event in Israel: karst, sandstone, and pedogenesis. GSI Bulletin 85. Geological Survey of Israel: Jerusalem, Israel

Shalom O, Crouvi O, Enzel Y, Rosenfeld D (2020) Locally recycled late Pleistocene loess feeds modern dust storms at the desert margins of the eastern Mediterranean, Israel. Aeolian Res 46:100612

Singer A, Ganor E, Dultz S, Fischer W (2003) Dust deposition over the Dead Sea. J Arid Environ 53(1):41-59

Singer A, Dultz S, Argaman E (2004) Properties of the non-soluble fractions of suspended dust over the Dead Sea. Atmos Environ 38(12):1745-1753
Smalley I, Marshall J, Fitzsimmons K, Whalley WB, Ngambi S (2019) Desert loess: a selection of relevant topics. Geologos 25(1):91-102

Soil Survey Staff (2014) Keys to Soil Taxonomy, 12th ed.; United States Department of Agriculture (USDA) \& Natural Resources Conservation Service (NRCS): Washington, DC, USA

Sow M, Goossens D, Rajot JL (2006) Calibration of the MDCO dust collector and of four versions of the inverted frisbee dust deposition sampler. Geomorphology 82(3-4):360-375

Swet N, Elperin T, Kok JF, Martin RL, Yizhaq H, Katra I (2019) Can active sands generate dust particles by wind-induced processes? Earth Planet Sci Lett 506:371-380. https://doi.org/10.1016/j.epsl. 2018.11.013

Turk JK (2012) Vesicular horizon distribution, properties, and pedogenic processes in deserts of the Western United States. Doctoral dissertation, UC Riverside, Riverside, CA, USA. Available online: https://escholarship.org/uc/item/325854wj (2021-11-25).

Turk J, Houdeshell C-A, Graham R (2016) A proposed master V horizon for the designation of near-surface horizons with vesicular porosity. https://www.nrcs.usda.gov/Internet/FSE_DOCUM ENTS/nrcs142p2_050844.pdf

Wieler N, Ginat H, Gillor O, Angel R (2019) The origin and role of biological rock crusts in rocky desert weathering. Biogeosciences 16(6):1133

WRB (2015) World Reference Base for Soil Resources 2014. Update 2015; World Soil Resources Reports 106; FAO: Rome, Italy; ISBN 978-92-5-108369-7

Wright J, Smith B, Whalley B (1998) Mechanisms of loess-sized quartz silt production and their relative effectiveness: laboratory simulations. Geomorphology 23(1):15-34

Wright JS (2007) An overview of the role of weathering in the production of quartz silt. Sed Geol 202(3):337-351

Yaalon DH, Dan J (1974) Accumulation and distribution of loessderived deposits in the semi-desert and desert fringe areas of Israel. Z. Geomorph. N.F. Suppl 20:91-105

Zilberman E (1992) The Late Pleistocene sequence of the northwestern Negev flood plains - a key to reconstructing the paleoclimate of southern Israel in the last glacial. Isr J Earth Sci 41:155-167 